

\section{Fantasmas, espectros, sirenas y otros zumbidos. Otros cuerpos recorren el mundo 1}

\section{Artículo de investigación}

Recibido: 15 de noviembre de 2019

Aprobado: 20 de febrero de 2020

\section{Jaidy Astrid Díaz Barrios}

Universidad Nacional de Colombia, Sede Bogotá jadiazba@unal.edu.co

Cómo citar este artículo: Díaz Barrios, Jaidy Astrid (2020). Fantasmas, espectros, sirenas y otros zumbidos. Otros cuerpos recorren el mundo. Estudios Artísticos: revista de investigación creadora, 6(9) pp 250-265. DOI: https://doi. org/10.14483/25009311.16241

Agradecimientos a la Vicedecanatura de investigación y extensión de la Facultad de artes de la Universidad Nacional de Colombia y la Société Pitouch Company de Estrasburgo.

Imagen 5. Millones de seres viviendo juntos en soledad 3 (Biecher E y Díaz Jaidy, 2019). Fotograma de uno de los videos que hacen parte del dispositivo escénico performativo.

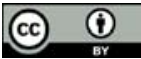

https://creativecommons.org/licenses/by/4.0/deed.es

\section{Resumen}

Desde la urgencia de la catástrofe humanitaria ocasionada por las grandes oleadas migratorias contemporáneas, interpelo la mirada sensible y critica que confronta estos hechos del horror. Fantasmas, espectros, sirenas y otros zumbidos. Otros cuerpos recorren el mundo, se propone una mirada sobre los cuerpos encallados en la mitad del mediterráneo, y otras dinámicas poéticas relacionadas con los cuerpos que se mueven, traspasan fronteras y habitan este planeta. Preguntas por cuerpos individuales y colectivos, en sus distintas agonías y sus formas de invisibilización. Resalto las formas de resistencias anidadas en el cuerpo como portador de deseos invencibles de atravesar un espacio. Descubro la historia y desempolvo la memoria con el ánimo de reconocer nuestra naturaleza Homo migrans. En oposición, a las ideas de frontera, dominio y bordes, despliego la creación de un "ecosistema de los que se mueven" visibles con la escritura de voces testimonio, ficción y detrito de sus cuerpos. Este documento es parte de los resultados del proyecto de investigación y creación: $L a$ rabia, el rastro, le noir, adscrito a la Vicedecanatura de investigación y extensión, de la Facultad de artes de la Universidad Nacional de Colombia, bajo mi dirección.

\section{Palabras clave}

Arte y migración; cuerpos fantasmas; cuerpos migrantes; derechos humanos; flujos migratorios; violencia 


\section{Ghosts, Specters, Sirens, and other Buzzes. Other Bodies Travel the World}

\author{
Abstract \\ From the urgency of the humanitarian catastrophe \\ caused by the great contemporary migratory \\ waves, I question the sensitive and critical gaze \\ that confronts these horror events. Ghosts, ghosts, \\ sirens, and other buzzes: other bodies cross the \\ world. We propose to take a look on the bodies \\ stranded in the middle of the Mediterranean, and \\ other poetic dynamics related to bodies that move, \\ cross borders and inhabit this planet. We raise \\ questions about individual and collective bodies, \\ in their different agonies and their forms of invisibi- \\ lity. I highlight the forms of resistance nested in the \\ body as the bearer of invincible desires to cross a \\ space. I discover history and dust my memory with \\ the intention of recognizing our nature as Homo \\ migrans. In opposition to the ideas of frontier, \\ domain and borders, I display the creation of an \\ "ecosystem of those who move" visible with the \\ writing of voices as testimony, fiction and detritus \\ of their bodies. This article is part of the results \\ of the research and creation project: La rabia, el \\ rastro, le noir of the Arts Faculty of the National \\ University of Colombia, under my direction.
}

\section{Keywords}

Art and migration; ghost bodies; migrant bodies; human rights; migratory flows; violence

\section{Fantômes, spectres, sirènes et d'au- tres bourdonnements. D'autres corps parcourent le monde}

\section{Résumé}

À partir de l'urgence de la catastrophe humanitaire provoquée par les grandes vagues migratoires contemporaines, je remets en question le regard sensible et critique qui fait face à ces événements d'horreur. Fantômes, fantômes, sirènes et d'autres bourdonnements : d'autres corps traversent le monde. Nous proposons de jeter un regard sur les corps laissés au milieu de la Méditerranée, et sur d'autres dynamiques poétiques liées aux corps qui se déplacent, traversent les frontières et habitent cette planète. Nous posons des questions sur les corps individuels et collectifs, dans leurs différentes agonies et leurs formes d'invisibilité. Je mets en évidence les formes de résistance nichées dans le corps comme porteur de désirs invincibles de traverser un espace. Je découvre l'histoire et dépoussière ma mémoire avec l'intention de reconnaître notre nature comme Homo migrans. En opposition aux idées de frontière, de domaine et de frontières, i'expose la création d'un « écosystème de ceux qui bougent » visiblement avec l'écriture des voix comme témoignage, fiction et détritus de leur corps. Cet article fait partie des résultats du projet de recherche et création : La rabia, el rastro, le noir de la Faculté des arts de l'Université nationale de Colombie, sous ma direction.

\section{Mots clés}

Art et migration; corps fantômes; corps de migrants ; droits humains ; flux migratoires ; violence 


\section{Fantasmas, espectros, sirenes e outros zumbidos. Outros corpos per- correm o mundo}

\section{Resumo}

A partir da urgência da catástrofe humanitária ocasionada pelas grandes ondas migratórias contemporâneas, questiono o olhar sensível e crítico que confronta estes eventos de horror. Fantasmas, espectros, sirenes e outros zumbidos. Outros corpos percorrem o mundo, propõe um olhar sobre os corpos encalhados na metade do mediterrâneo e, outras dinâmicas poéticas relacionadas com os corpos que se movem, transpassam fronteiras e habitam este planeta. Perguntas por corpos individuais e coletivos, em suas distintas agonias e em suas formas de invisibilização. Ressalto as formas de resistência aninhadas no corpo como portador de desejos invencíveis de atravessar um espaço. Descubro a história e tipo o pó da memória com a intenção de reconhecer nossa natureza Homo migrans. Em oposição às ideias de fronteira, domínio e bordes, mostro a criação de um "ecossistema dos que se movem" visíveis com a escrita de vozes testemunha, ficção e detrito de seus corpos. Este documento é parte dos resultados do projeto de investigação e criação: La rabia, el rastro, le noir, anexo à vice-reitoria de investigação e extensão, da Faculdade de artes da Universidade Nacional da Colômbia, sobre minha direção.

\section{Palavras chave}

Arte e migração; corpos fantasmas; corpos migrantes; direitos humanos; fluxos migratórios; violência. luarispalla kauangapa mana kai atun Llagtapi tiaska

\section{Maillallachiska}

Parlakumi achka kauaikuna kai atun Llagtapi mana tiaska llapa atun taimiasi samuska chiura challamuska karumanda mana rigsiskakuna, kawari kallariska iapa jiru paikunapagpi mana kawaska, sug kunata kawari sugkunata manima mancharunkuna iapa tiami Achka mana iachankuna maimandami challamuska sug iacha mandadur Universidad Nacional sutimanda.

\section{Rimangapa Ministidukuna}

Rusaikuna llugsii sug simama; jiru kauaikuna; sugnimanda challamuskakuna; Nukanchipa kausaita kauachisunchi; Achka samuska sugmimanda kaipi kausangapa mana allillakausai. 


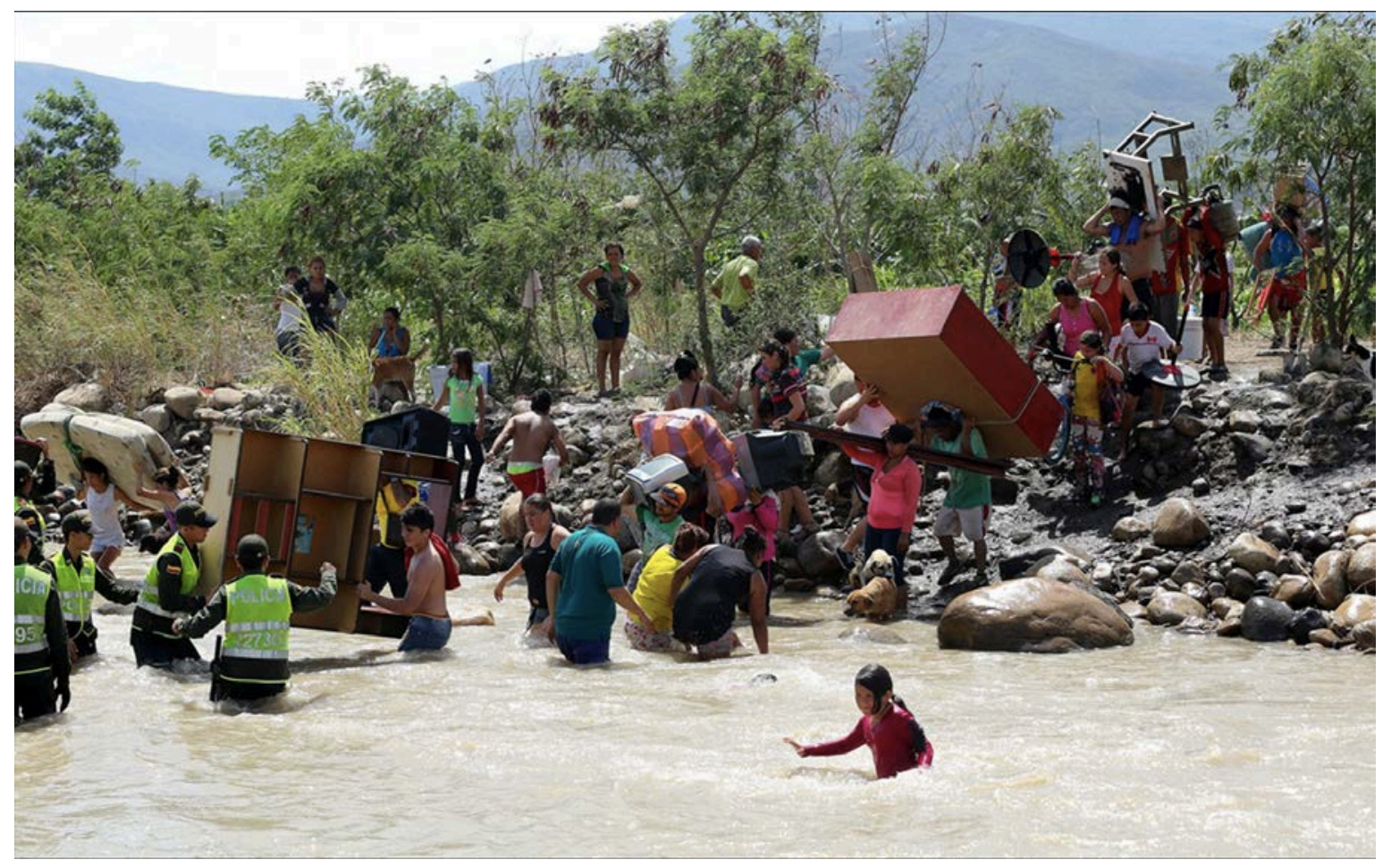

Imagen 1. Paso del río fronterizo entre Colombia y Venezuela. [Fotografía]. Recuperado de «https://tvenlacalle.com/suceso/ aparecieron-cuatro-de-seis-ahogados-cuando-cruzaban-rio-fronterizo/»

Dedicado Fantasmas, espectros, sirenas y otros zumbidos, a aquellos cuerpos se detiene sobre estos "cuerpos encallados" en que reclaman su derecho a moverse para existir y habitar en la tierra que conquistan tras abandonarlo todo, menos su humanidad.

Ahora silencio / Que todo se detenga / Ellos pasan (Huberman, 2018)

\section{Uno}

En los últimos años, millones de seres humanos han abandonado sus países de origen, huyendo del hambre, de la guerra, del reclutamiento forzoso, del despojo de tierras, del cambio climático... o simplemente imaginando una vida distinta. Una coreografía de movimientos compleja se desarrolla sobre las tierras y los mares de este planeta. Migrantes, refugiados, exiliados, nómadas, trashumantes, ciudadanías fuera del sistema, atraviesan un complejo sistema de violencias y sufrimientos. la mitad del mediterráneo, en el tránsito desde el Norte del África a la isla de Lampedusa.

El cuerpo como portador de deseos invencibles atraviesa espacios inimaginables, políticas, éticas y estéticas, ávido de lugar. Y luego queda su rastro: objetos, marcas, espacios, cantos, voces, sonidos que se descubren también como arrullo, duelo y lugar de afecto social, pero que también, es solo otro detrito más de estas humanidades. Resuena la voz como testimonio, testigo y huellas de cuerpos complejos al borde de ser algo.

El sistema de protección a ultranza de fronteras, de estigmas y prejuicios sobre la figura del extraño, intruso, extraniero o simplemente aquel que se moviliza, ha sido el escenario vivo en el que se suceden gestos de resistencia y de sobrevivencia, de pérdidas y encuentros, de solidaridad y odio. "No nos gusta que nos llamen de refugiados entre nosotros mismos", escribe Arendt, "preferimos 
llamarnos emigrantes o recién llegados", (1994, p. 110), yo también lo prefiero.

\section{Dos}

Transitar designa un estado, una sensación, una expansión que a lo largo de la historia del hombre ha generado y regenerado ciudadanías, individuos y grupos humanos. Nunca, ese transitar por la tierra ha estado tan normatizado y regulado, tanto que, incluso hoy, las ilegalidades y criminalidades se imponen. Este sistema de protección a ultranza de fronteras, de estigmas y prejuicios sobre la figura del extraño, intruso, extranjero o simplemente aquel que se moviliza, ha sido el escenario vivo en el que se suceden gestos de resistencia y de sobrevivencia, de pérdidas y encuentros, de solidaridad y odio. Pasar, cueste lo que cueste es la única opción para muchos y la Declaración Universal de Derechos Humanos así también lo garantiza.

1. Toda persona tiene derecho a circular libremente y a elegir su residencia en el territorio de un Estado.

2. Toda persona tiene derecho a salir de cualquier país, incluso del propio, y a regresar a su país. (Asamblea General, 1948, Artículo 13)

1. Toda persona tiene derecho a una nacionalidad.

2. A nadie se privará arbitrariamente de su nacionalidad ni del derecho a cambiar de nacionalidad. (Asamblea General, 1948, Artículo 15)

Del mismo modo, el pacto mundial para la migración expresa este compromiso en el que se adhieren gran parte de los gobiernos de países del globo.

El presente Pacto Mundial expresa nuestro compromiso colectivo de mejorar la cooperación sobre la migración internacional. La migración ha formado parte de la experiencia humana desde los albores de la historia, y reconocemos que genera prosperidad, innovación y desarrollo sostenible en nuestro mundo globalizado, y que estos efectos positivos pueden optimizarse mejorando la gobernanza de la migración. En el mundo actual, la mayoría de los migrantes viajan, viven y trabajan de manera segura, ordenada y regular. Sin embargo, no cabe duda de que la migración tiene efectos muy distintos y a veces imprevisibles en nuestros países y comunidades y en los migrantes y sus familias. (Asamblea General de las Naciones Unidas, 2018 p. 39)

\section{La isla}

Lampedusa es una pequeña isla ubicada en el mar mediterráneo, cuyo territorio es africano por estar más cerca a este continente, pero gobernado por Italia. Esta isla, situada a media distancia del nordeste africano y el sudeste europeo presenta varias paradojas, y en medio del mar mediterráneo parece una visión dantesca del infierno para unos o el purgatorio para pocos. Algunas de esas paradojas provienen de la crisis humanitaria que sufren diversos países del continente africano, en donde sus gentes, por distintas razones deciden desplazarse, moverse de su lugar de origen. Preferir "descansar (como sinónimo de muerte) en el mar" a vivir en sus lugares de nacimiento, es para muchos la única esperanza y ruta posible.

Lanzarse al mar, a su inmensidad, es lanzarse a la vida con la idea de pasar, es la oración que hermana argelinos, tunecinos, marroquíes, libios, saharianos, senegaleses, sirios...

El fenómeno de desplazamiento ha alcanzado cifras cada vez más altas, millones de seres humanos han abandonado sus países de origen, huyendo del hambre, de la guerra, del reclutamiento forzoso, del tráfico de personas, del despojo de tierras, de la expulsión del territorio, del cambio climático, de la poca oportunidad, de la perspectiva religiosa, ideológica o simplemente porque sí, aunque este segmento se cobija por el deseo de derivar, explorar, perderse... o mejor largarse del mundo.

Sin embargo, nunca había sido tan ilegal moverse entre fronteras como ahora. Migrantes, refugiados, exiliados, nómadas, trashumantes, ciudadanías fuera del sistema, atraviesan un complejo sistema de violencias, prohibiciones y atentados a sus derechos que, por supuesto impactan directamente su cuerpo, su cuerpo por ser sistema de transporte y locomoción, por ser casa, por padecer hambre y enfermedad, por defecar, por comer, por reproducirse o como chivo expiatorio de un colectivo, como carne sensible, como contenedor de esperanza y deseos, por tener pensamiento, por ser un arma de resistencia. 


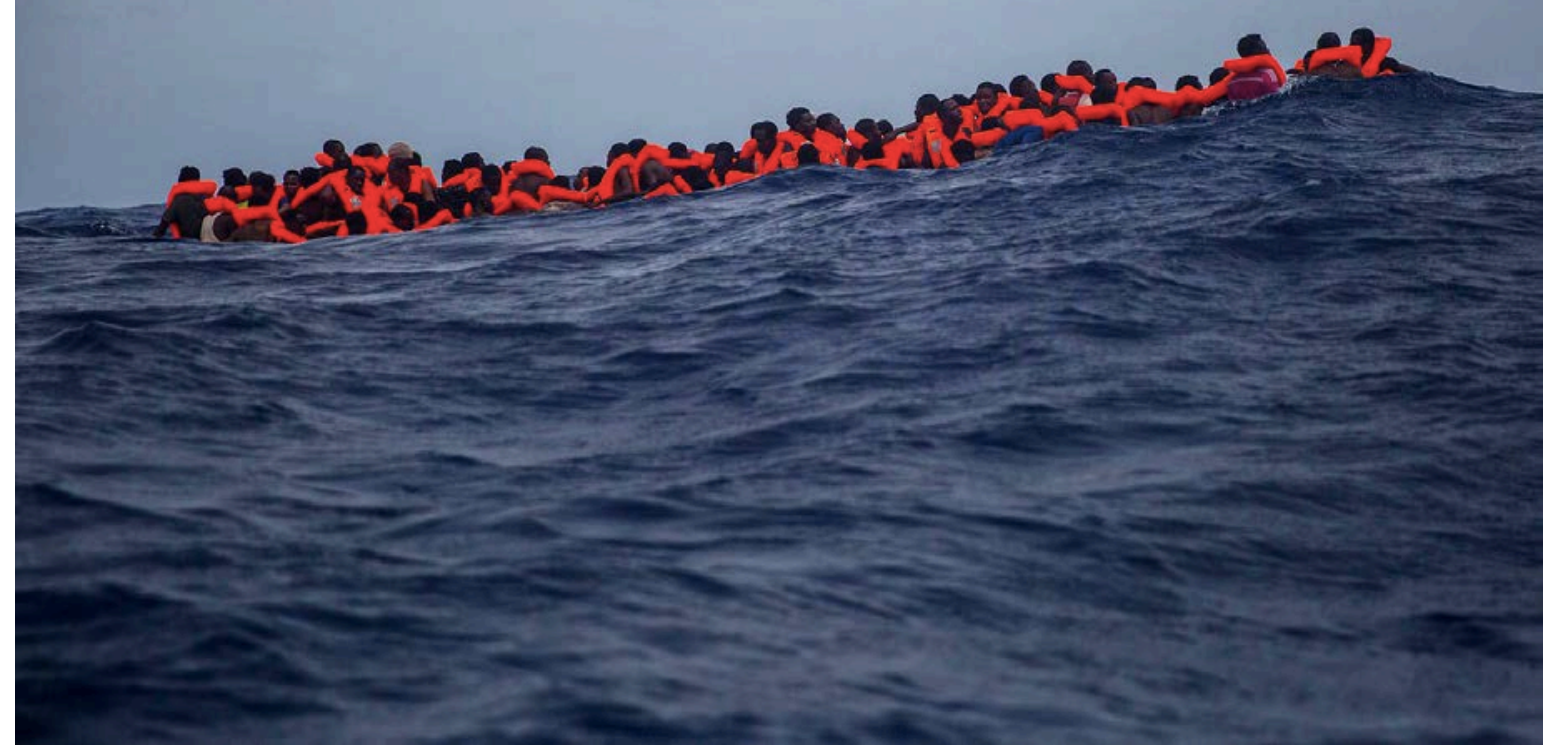

Imagen 2. Palacios S/AP (2020) ONG Proactiva Open Arms en el Mar Mediterráneo a unas pocas millas de Libia. [Fotografía]. Recuperado de «https://www.infobae.com/america/fotos/2017/07/26/muerte-en-el-mediterraneo-las-tenebrosas-fotos-de-los-migrantes-naufragos/»

De lo que hablo hoy -de lo que me da rabia- no es de los migrantes, de los que se echaron de casa, de su lugar natal, lo que me produce rabia es la política hostil de acogida o rechazo, común a todos los países del mundo, en sus dimensiones de nación y ciudadanías.

Eso de lo que hablo hoy, es de la diferencia entre la vida y la muerte. De la diferencia de humano e inhumano.

Detrás de la atrocidad de criminalizar la solidaridad como en las aguas del mediterráneo en Lampedusa, de cerrar fronteras, de negar oportunidades, está la mala propaganda, las falsas noticias, las cifras alteradas, la desinformación, las trampas de los imaginarios colectivos sobre el que abandona su lugar de origen y claro, la cruel política de los partidos de extrema.
Se alzan a diario políticas invitando a defender la soberanía de la nación, a erigir todas las formas posibles de Frontex ${ }^{2}$ que avivan los campos de concentración e ideas nacionalistas que alimentan la exclusión, la violencia, la indiferencia, la homogeneidad, en ultimas el fascismo. Todas estas acciones buscan poner en negativo la presencia del que migra (inmigrar o emigrar da igual). Ocultar la atrocidad. Dejar morir en el mar, penalizar la solidaridad es de lo que deberíamos escandalizarnos como humanidad.

En el mediterráneo, a esta hora, en este momento, 35 personas, de nuestra familia humana explotan sus pulmones tragando el agua amarga de la ignominia humana. El cuerpo único instrumento de vida pierde toda dignidad.

\footnotetext{
2 Cf. Agencia Europea de la Guardia de Fronteras y Costas.
} 
Así, el Mediterráneo es escenario de una situación doblemente vergonzosa: la crisis humanitaria de los inmigrantes a la deriva y el acoso legal que sufren las ONG que intentan rescatarlos. Esta es la postura de demasiados gobiernos de la Unión Europea, que través de mentiras tóxicas, el racismo latente y la prepotencia de la inmunidad pone sobre la mesa la discusión por el derecho internacional marítimo y el derecho a la humanidad. ¿Tremenda paradoja no?

Sentir una profunda vergüenza ante el comportamiento inhumano que hemos tenido los hombres, no importa si es Europa, África, Latinoamérica o Asia, durante estos años frente al drama de los migrantes en el mar, pero que son símbolo de los migrantes de tierras y aires. Todos de cara al desastre de ser migrante ilegal y pobre.

\section{La lucha en superficie: El ahogo. Cuerpos que flotan}

La "lucha en superficie" por respirar, es el ahogo. Morir por ahogamiento en el agua no es ni bonito ni indoloro, aunque puede ser rápido. Cuando una víctima se da cuenta de que no puede mantener su cabeza sobre al agua, tiende a sufrir un ataque de pánico, llega la "lucha en superficie", recoge el aire en la superficie y aguanta la respiración cuando se sumerge. Su cuerpo está en posición vertical, agitando sus brazos débilmente, como si intentará subirse a una escalera inexistente en el mar. Una o dos veces más vuelve a salir rápidamente, recoge el aire en la superficie y aguanta la respiración cuando se sumerge.

Luego, inhala algo de agua, balbucea, tose e inhala más agua. El agua en los pulmones bloquea el intercambio de gas en los delicados tejidos, al mismo tiempo la inhalación de agua sella y bloquea las vías aéreas, es un reflejo llamado laringoespasmo o laringismo.

Existe una sensación de lloro, y una quemazón en el pecho a medida que el agua desciende por las vías aéreas. Luego viene esa especie de caída en una sensación de calma y tranquilidad. Es la muerte. Esta coreografía macabra dura entre $20 \mathrm{Y}$ 60 segundos y se repite cada día. Ahora mismo.
Esto es atroz y me causa una angustia insoportable. Ustedes disculpen, el horror de este relato, pero les pido que me acompañen en esta agonía colectiva, que es la agonía de la humanidad, de la solidaridad. Ya alguien pedía compañía, narrando los hechos de los campos de exterminio en Polonia.

Este teatro del horror del paisaje marino se alza todos los días sin saberlo. Cuerpos migrantes en la miseria sumergidos no tan solo en el mar, sino en la invisibilidad, en la sombra, una sombra espesa de la que es casi imposible salir. Es un cuerpo invisible. Si lo ponemos a la luz, se hará visible sin duda, pero no por ello dejará de proyectar una sombra en algún lugar: ese cuerpo migrante es en sí mismo la sombra. La oscuridad del ajeno, del intruso, del migrante en miseria. Es su (no) destino.

Aquí el vacío: allí el mar, allí las balsas, allí la política, allí el agua, allí la incertidumbre, allí la sal, allí la zozobra, allí los peces, allí la xenofobia, allí los negros, allí la prensa, allí los árabes, allí la hambruna, allí los libios, allí los náufragos, allí la oscuridad, allí el temor, allá la distancia.

\section{Poner el cuerpo}

¿Cómo dejar indefenso un cuerpo? ¿Cómo dejarlo morir?

El que sale de casa, el que deja su hogar, el exiliado, el paria, el refugiado, el disidente, el aventurero, aún el turista en su trivialidad, todos ellos ponen sus cuerpos, se lo juegan.

Al otro lado de la isla, a 20 kilómetros, el turismo de gama alta europeo broncea su pálido cuerpo en la playa, en tierra firme y se baña en las mismas aguas del mediterráneo, pero con otras olas.

Jugarse el cuerpo significa ir allí donde ocurre la tragedia y quedarse, con nuestra presencia, nuestras necesidades vitales, nuestra resistencia. El cuerpo es el medio de lucha más extremo que existe en la tradición de la no violencia. Poner el cuerpo, comprometerse activamente sería una medida. ¿Qué pasaría si los preciosos cuerpos de nuestros protagonistas "de Netflix", se jugaran el cuerpo subiéndose a las pateras (los barcos) e hicieran presencia allá? ¿Qué pasaría si los culos 


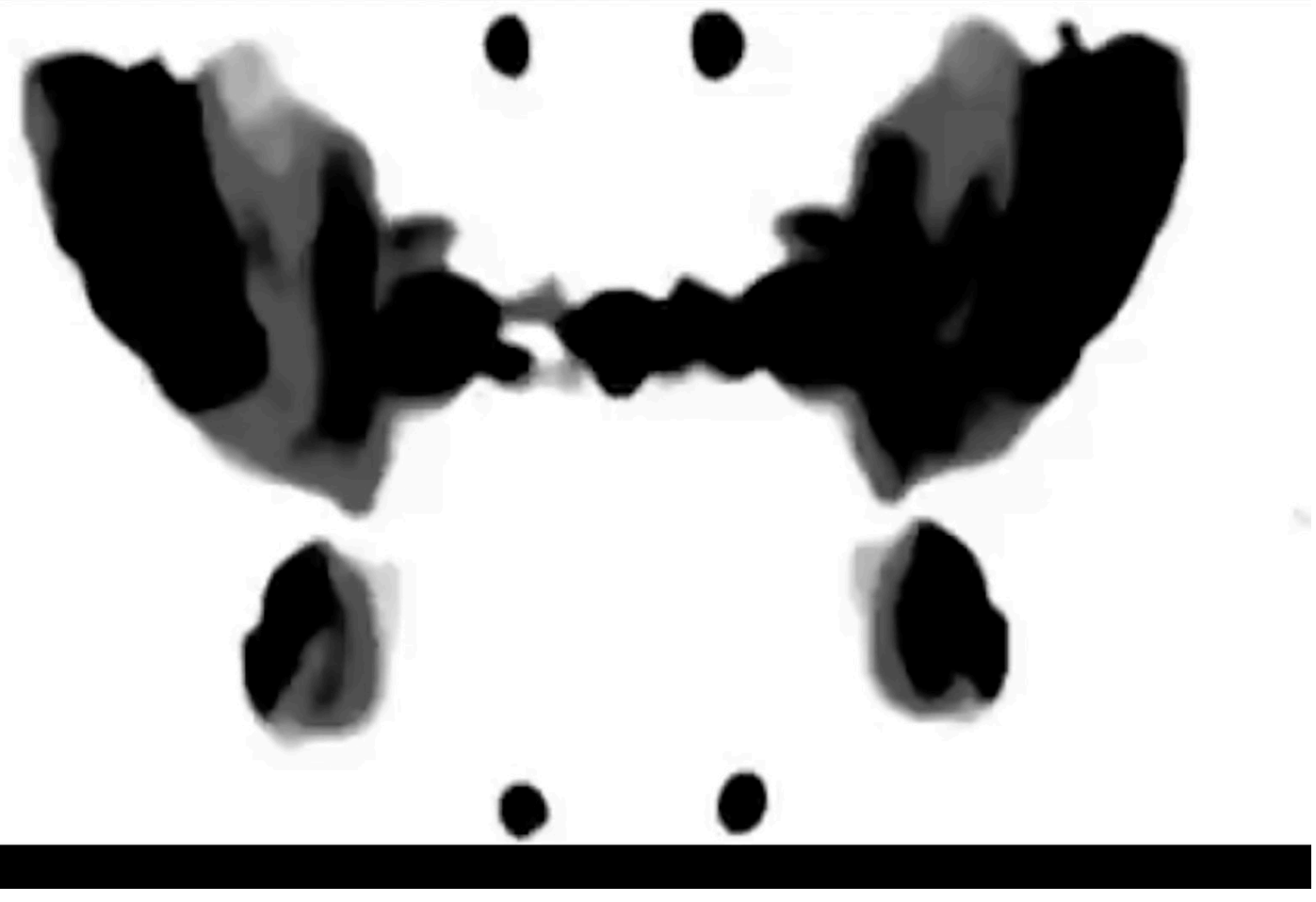

Imagen 3. Millones de seres viviendo juntos en soledad 3. (Biecher E y Díaz Jaidy, 2019). Fotograma de uno de los videos que hacen parte del dispositivo escénico performativo.

tonificados y los vientres planos de los más bellos actores y actrices se jugaran el cuerpo arrojándose al mar? ¿Si nuestros políticos se jugarán sus cuerpos de panzas abundantes y llenas subiéndose al barco, habitando las carpas, los escampaderos de venezolanos o de los indígenas del Cauca, Bolívar y Caquetá?

Quizá es el momento de pasar a la acción y jugarnos directamente el cuerpo. Porque somos un cuerpo, y el cuerpo es la vida misma. ¿Qué pasaría si nos jugamos el cuerpo?

\section{En el itinerario a Lampedusa}

Efectos y objetos que llevar: 2 camisas, 2 calzones, 2 sujetadores, 2 pares de calcetines de lana, 1 camiseta de lana, 1 pasamontañas, 1 jersey, 1 manta, 1 par de zapatos de recambio, cordones, hilo y aguja, botones de pantalón, jabón, cantimplora, bol, tenedor, cuchillo y cuchara, linterna, brújula, arma si es posible, eventualmente saco de dormir. Llevar ropa puesta de abrigo, una gorra, un impermeable, un buen par de zapatos con suela de goma.

Venir con documentación incluso falsa, pero perfectamente en regla, con permiso de trabajo para pasar los controles; además, traer cartillas de racionamiento y hojas de cupones. Estas últimas son indispensables para facilitar el aprovisionamiento.

\section{$[\ldots]$}

Inhalar - largo silencio

[...] No soy nadie para ti.

[...] Una organización benéfica descubrió que esos europeos había muerto años antes, adivina cómo... En un velero atrapado en una terrible tormenta 


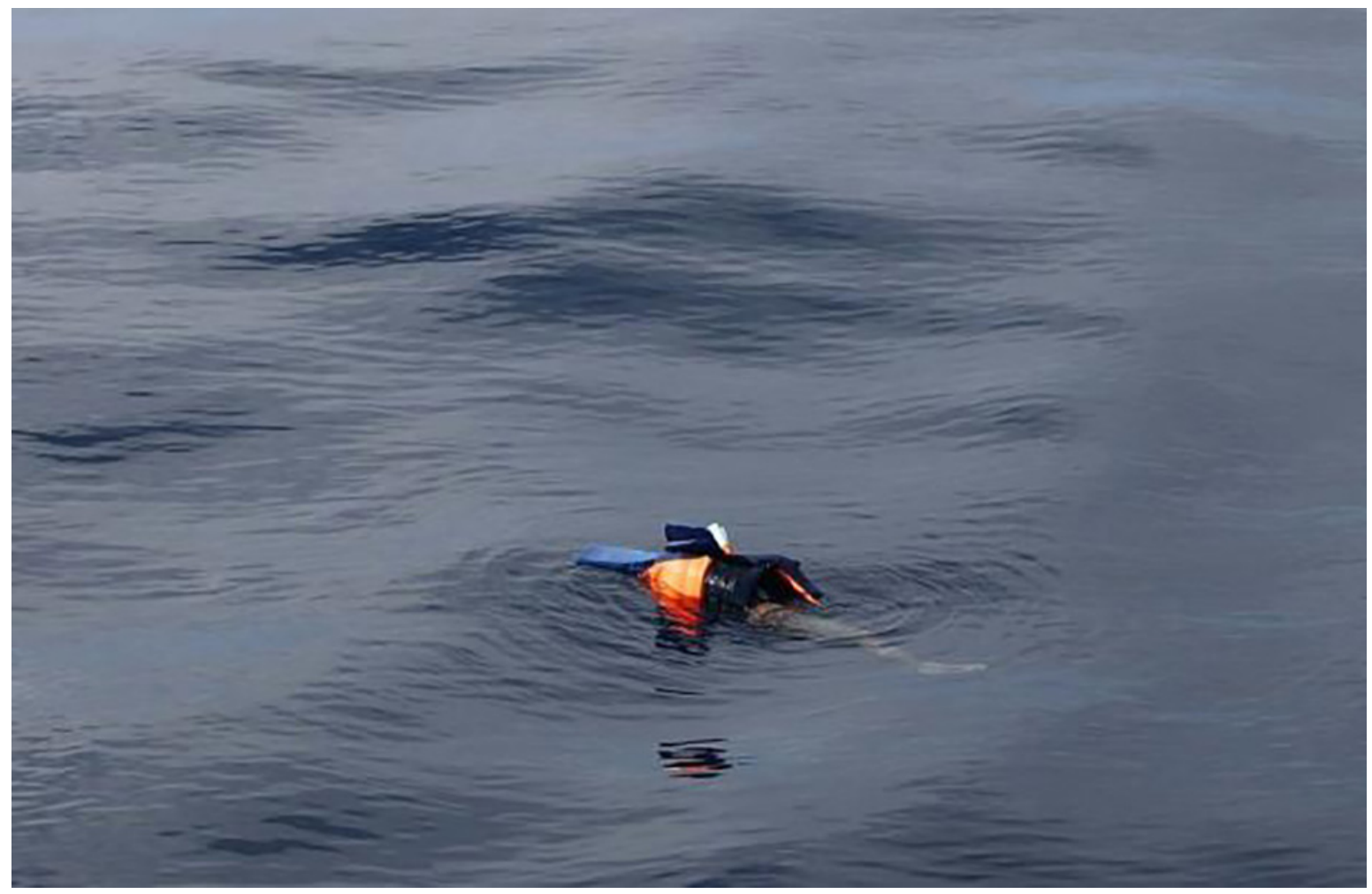

Imagen 4. ONG Proactiva Open Arms en el Mar Mediterráneo a unas pocas millas de Libia (Palacios S/AP, 2020) [Fotografía]. Recuperado de «https://www.infobae.com/america/fotos/2017/07/26/muerte-en-el-mediterraneo-las-tenebrosas-fotos-de-los-migrantes-naufragos/»

dirigiéndose hacia África... adivina qué más, nunca encontraron sus cuerpos...

Deben estar aquí... en estas aguas...

[...]

Me estoy pudriendo en el agua como una hoja.

Me siento tan extraño... mi corazón flota... Se siente como un barco de papel en un saco de cuero lleno de agua tan lleno que explotará...

Casi me hace reír... tal vez este barco llegará a Lampedusa...

Pero antes de que el barco se derrame fuera del saco...

Fuera de este cuerpo quiero decir...

[...] Dejemos que nuestros hijos crezcan sin esperanza.

Es mejor.

Cierra la puerta a la bondad... Odio la bondad, apesta. como comida podrida, como basura, como pescado seco...

Si realmente quieres hacer algo por mí y por aquellos como yo...

Cómpranos un crucero... déjanos viajar por una semana

en una importante nave...

No te preocupes si somos cadáveres sin forma

si sólo somos las sobras de la cena del pescado...

A alguien le falta una pierna, a otro la cabeza...

No nos ves... giras hacia el otro lado... $[\ldots]$

Inhalar - largo silencio

[...]

El agua deshace su círculo derecho... cambia... 
Se tambalea como una hoja, se mece, pero pierde la forma.

Mi cabeza roza contra ella... no pasa nada.

Pero es la señal.

Tengo mi período.

Tengo agua en mis pulmones. Tengo miedo.

No puedo gritar.

¿Es la muerte como estar amordazado?

[...]

Me lo contaste: me dijiste que me mantu-

viera alejada de todo el mundo cuando

tuviera la regla,

el olor de la sangre saca a los peores

monstruos.

Viejos almirantes de la marina perdidos en el abismo...

¿Y si son cappittallisstts?

Me hundo con mi rastro de sangre...

El rastro rojo se desvanece en las

profundidades...

Es la última línea que dibujaré...

Con la muerte mensual de un niño

me explicaste que si no hay espacio para lo

que debe suceder

puedes exprimir un poco de sangre, forzar

el cuerpo a entrar...

iEsta vez no funcionó!

¿Por qué no han parado el naufragio y la

pérdida de conciencia

el tiempo, el espacio, el cuerpo, la sangre,

miedo, violencia, historia,

la memoria, la moralidad, los elementos

mismos?

¿por qué no han dejado

los viajes, el hambre, la economía

intereses del estado, la explotación, el

monstruo,

el barco, la luna, el viento,

esta calma muerta, la diarrea, los peces,

la humedad, la bronquitis, la tarjeta postal,

la misión, la roca, la ilegalidad,

la emigración...?

[...]

Inhalar - largo silencio

[...] Ya no tengo un cuerpo para enviarle de vuelta.

[...] Me hundo entre pasaportes falsos bolsas de plástico, jeans desgastados, un montón humano vacío de huesos, papeles descoloridos... sándwiches a medio comer...

un solo cepillo de dientes...

un solo cepillo de dientes entre 700

ilegales...

Esta es la herencia del naufragio.

[...] Dondequiera que vayas, dondequiera

que te encuentres como extranjero,

rezar por Shauba, por su cuerpo y su alma, ya son dos cosas separadas...

uno viaja al fondo, el otro no lo sé...

...me saca de esta humedad...

...me pondrán bajo cualquier sol cualquier

día...

(Prosa, 2008). ${ }^{3}$

\section{Lo que está pasando con los inmi- grantes en el Mediterráneo es un genocidio}

Ustedes podrán pensar que exagero, ¿qué es mi propio drama el que habla? Pero no importa, ino creen que sería decisivo que alguno de ustedes se animara a jugarse el cuerpo? Sacrificándose, exponiéndose, claro está, porque el cuerpo es cuerpo y no hace concesiones, y si está allí, no puede estar aquí. Si se está muerto ya no puedes estar vivo.

Veronessi ladra con su deseo de ser perro y aullar o gritar "Cuando alguien corre peligro de muerte, no le pedimos el carné de identidad. Cuando recibimos un SOS de personas que mueren, antes de pensar en "salvar sus almas" hay que hacer una cosa: salvar sus cuerpos". (Veronessi, 2019, p. 33).

Comida llena de tierra, escasa tierra para permanecer, autos con fondos interminables. Cuerpos en penas. Uñas demasiado largas, infinitos deseos de vivir. Pieles oscuras como el pasado, caras negras como el futuro. Cuerpos vivos amontonados en el suelo. Cuerpos muertos amontonados en el suelo. Cuerpos fatigados impulsados por el sueño, errando sin rumbo, rumbeando encuentros. Asco en las miradas. Pasar la raya, pasar la frontera, vigilancia y paranoia. Nadie es bienvenido. Como un animal salvaje buscando un agujero atrapado

\footnotetext{
3 Traducción Jaidy Díaz (2019). Lampedusa Beach [Playa
} de Lampedusa]. Bogotá, Colombia. 
en el limbo de la imagen del extranjero. Cuerpos malolientes. Culitos de niño. Cuerpos sudados. Cuerpos sangrientos. Cuerpos ahogados. Cuerpos gaseados. Cuerpos violados. Cuerpos enfermos. Cuerpos desgastados. Cuerpo cicatriz. Retorno del extranjero como espectro. Cuerpos que ladran horror. Cuerpos sexo. Cuerpos ron. Culos meneando su calor, nuevas putas, otras larvas. Grandes tetas apuntando al sur, órganos descompuestos que no saben más que son. Cuerpos testimonios, testamentos.

\section{La extranjera asesina: Medea}

Huérfanos, solitarios, extraviados... uno tras otro pasan, a veces cruzados, otras fugaces, solos... los sonidos escuchan las voces ¿De dónde vienen, adónde van? Pasan, igual que las voces de los cuerpos que los producen. Entre paisajes sonoros y palabras, se elaboran uno a uno como un laboratorio de física. Viajan, permanecen, regresan. La voz se levanta, se expone, se pierde. Se crea un espacio. Escucha.

Medea era una maga venida de Oriente, que ayudó a Jasón a hacerse con el legendario vellocino de oro y que, madre cruel, mató a sus dos hijos como venganza contra su marido, ciega de amor o de odio. Ella es la mujer que se rebela contra lo establecido, contra su familia, su nación y su amor. Ella es la mujer que mata a sus hijos. Autónoma, bárbara, rebelde, heroína, poderosa, bruja, traidora, esa es la encarnación de Medea. Pero hay otra revisitación al mito; Medea (Wolf, 1996), se presenta de otra manera, que se remonta a versiones anteriores a los trágicos. Aquí, Medea no mata a sus hijos, pero es culpada por ello, al ser la maga poderosa, la mujer y la extranjera en Corinto. El estigma de lo extraño aparece como figura. La falsa noticia, la propaganda, el chivo expiatorio, la estrategia para avivar la conciudadanía.

La figura de Medea aparece como una mujer extranjera repudiada en tierras extrañas y acusada falsamente, para mantener el orden social de una ciudad en dónde no nació. Medea engendra el miedo, forma parte de una categoría de la alteridad, de lo extraño y misterioso, entre los griegos. Con este asesinato, Medea se convierte en bárbara. En resumen, ella simboliza lo Otro que se reafirma y se levanta contra la encarnación de lo estipulado y el orden representado por Jasón. El estatuto de extranjera, de extraña, se mostraba ante el público griego para comprender la acción asesina: un crimen tan atroz (matar a sus propios hijos) no podía provenir de un conciudadano; debía ser ejecutado por una extranjera, no por una mujer griega. Medea es la representación de la migrante, alguien a quien debe temerse.

El miedo, como una sombra también, transforma profundamente nuestra relación con el cuerpo, con el tiempo, con el próiimo y con nuestro propio pensamiento. " [...] Andamos desorientados en la significación que atribuimos a las impresiones que nos agobian y en la valoración de los juicios que formamos".

El miedo hace resurgir el fantasma de lo primitivo en nosotros, de tal modo que el miedo no es solo a la muerte, sino el miedo al otro, miedo al tiempo incierto: es un miedo ante el retorno de lo reprimido en general, un miedo a todo lo que nuestro estado de "cultura" considera malo y no por casualidad utiliza para nombrarlo las palabras de lo primitivo, "barbarie", "salvajismo", “atraso", "bestialidad".

Mientras escribo estas líneas, enero 5 de 2019 el clamor del pueblo venezolano pide la destitución de Nicolás Maduro, las manifestaciones de los Chalecos Amarillos en Francia dejan víctimas fatales de lado y lado, balas de caucho se insertan en los rostros de una generación que desconoce la pobreza extrema y las atrocidades de la guerra, gritos a favor de la vida de las mujeres Ilenan las plazas de Cataluña en España, de Cuenca en Quito y con pesar, su silencio en Cali, Colombia. Complots imaginarios y reales crecen muros en las fronteras y apuntan sus armas nucleares al espacio aéreo. Parece que nada se escapa a esta horda de deshumanidad. Se niega a las personas a ser escuchadas a pronunciarse, imbricando un asunto ético y político sobre la dimensión concreta de una voz. ¿Cuál es el destino de una ciudad que no escucha a sus habitantes? y ¿cuál es el destino de una ciudad que restringe la posibilidad de ser habitada en distintas temporalidades en sus arquitecturas, calles, plazas, hospitales, mercados, no lugares? 


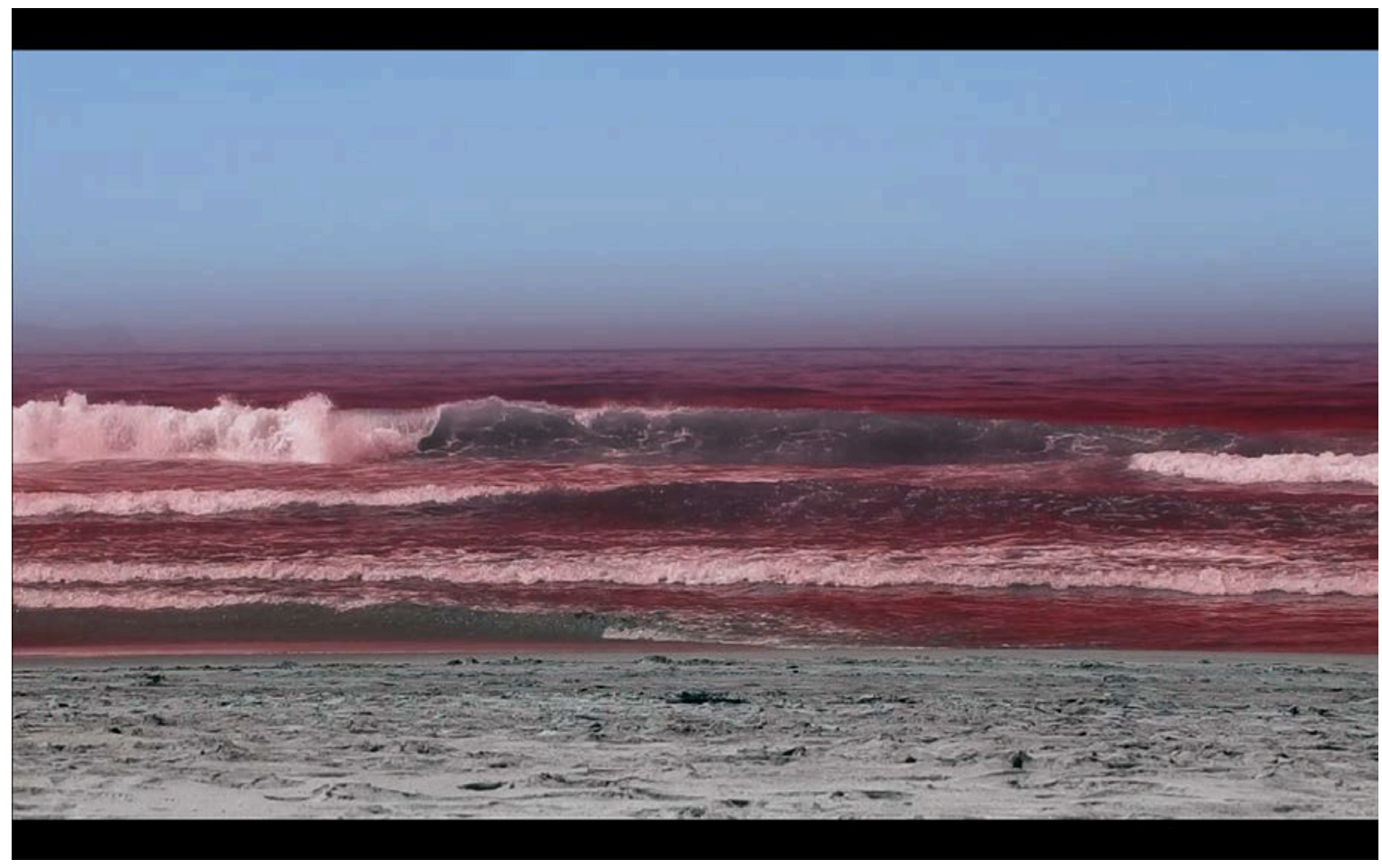

Imagen 5. Millones de seres viviendo juntos en soledad 3. (Biecher E y Díaz Jaidy, 2019). Fotograma de uno de los videos que hacen parte del dispositivo escénico performativo.

\section{Poner el cuerpo II}

Poner el cuerpo es una manera de hacer de escudo y de subrayar a la amenazadora mayoría que apoya lo que está pasando con los inmigrantes, una mayoría que suplica por el cierre de fronteras, que exalta al nacionalismo, que inculpa. Todas esas políticas son un inhumano error, fruto de la propaganda política, el oportunismo y la desinformación.

Nos hemos protegido, hemos querido continuar con nuestras vidas, proteger nuestros cuerpos, nuestras familias, mientras miles de personas pierden su vida en el mar, en el río, en la montaña, da igual en dónde.

\section{Desear largarse \\ Desear otra vida \\ Desear pasar \\ Desear llegar \\ Desear vivir}

\author{
Desear un Mercedes Benz \\ Un rolex \\ Un mejor seguro social \\ Ganar el triatlón \\ Tomar agua limpia de la llave \\ Un viaje \\ Estudiar \\ Cagar en un inodoro \\ Profesar \\ Ser blanco \\ Comer en Hooters \\ Tener tetas \\ Ser artista \\ Imaginar \\ Intentar
}

Decenas de muertos deja el camino, no existe atrás.

iimpossível de ver! impossible to look!

iimpossibile da guardare!

iunmöglich zu sehen!

ilmposible de ver! 


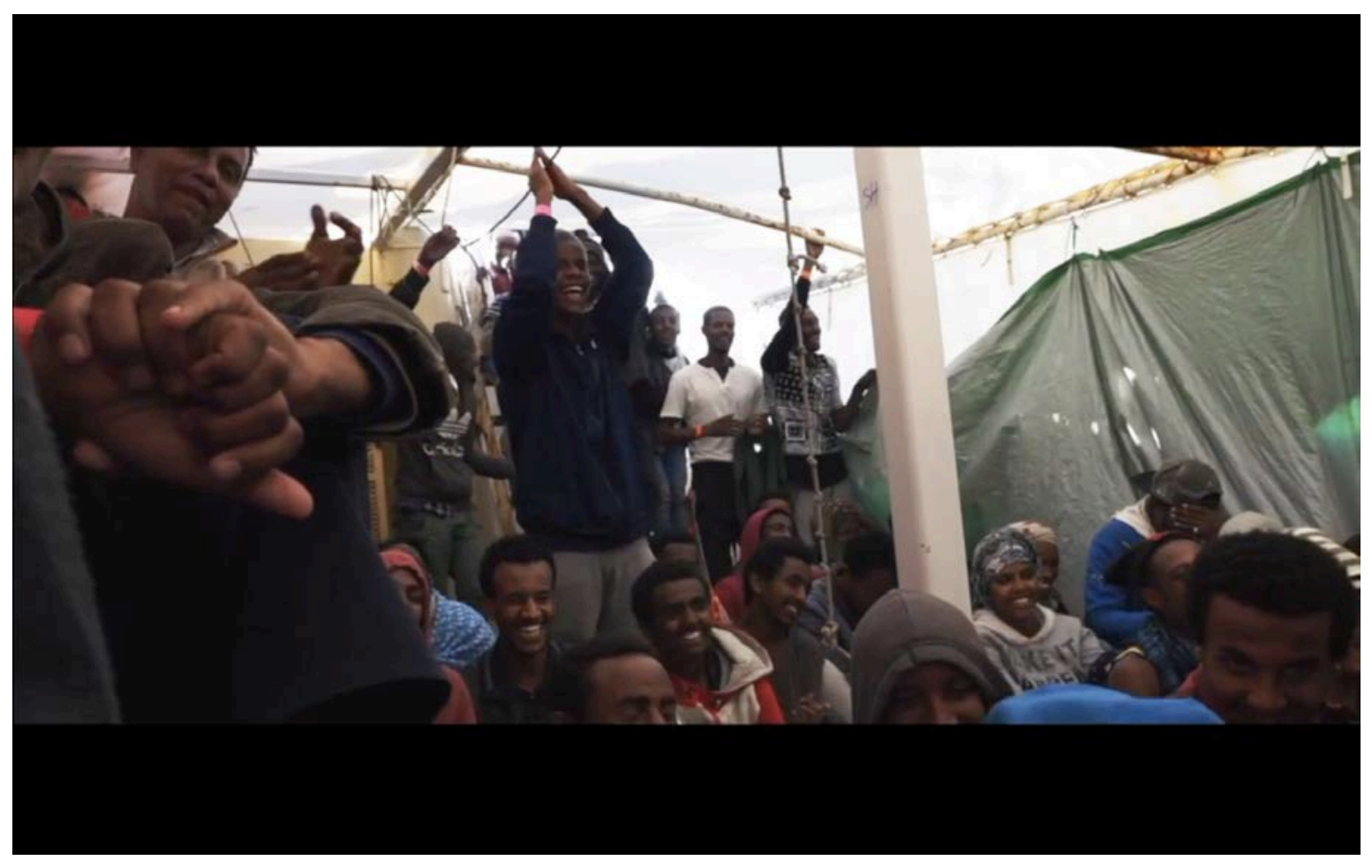

Imagen 6. Millones de seres viviendo juntos en soledad 3. (Biecher E y Díaz Jaidy, 2019). Fotograma de uno de los videos que hacen parte del dispositivo escénico performativo.

iimpossible à regarder!

iMbëggeel!

\section{Hoy}

Ahora el Mediterráneo rebosa literalmente de cadáveres. Es el cementerio marino de la ignominia. Como consecuencia de esto la humanidad naufraga y la sombra continua.

El miedo se sigue propagando, el miedo enfrenta a las naciones, a los ejércitos, a los grupos, a los hombres. Se instala como un fantasma en el hueco, en el corazón de cada psique. Y crea en ella un conflicto permanente entre mociones pulsionales contradictorias.

Ese sentimiento, asociado a la prepotencia que ofrece la inmunidad, se ha generalizado hoy en el común, no es exclusivo de las instituciones. Desgraciadamente hoy asistimos a inconcebibles episodios de racismo, exclusión, maltrato y violencias.

Las bellas aguas azuladas del Mediterráneo descomponen los miles de cadáveres submarinos, sus olas arrastran la peor de las pérdidas, lo inhumano, sus corrientes atraviesan todos los mares, recorren las geografías, los estados, las lenguas, pasa por el Golfo de México, se contorsiona con el mar caribe pasando por Guatemala, Honduras, Haití. Aquí su corriente fría atraviesa y fecunda el río Táchira, golpea fuerte en Colombia. El clima es el mismo. Hay algo que hermana al mar Mediterráneo y su flujo migratorio con nuestro país. Un fantasma nos recorre, de México a Estados Unidos, de Venezuela a Colombia, de Colombia a Chile, de Venezuela a Perú, al Brasil, al Ecuador, de Haití a Chile, de Haití a Colombia, de Honduras a México, de México a Estados Unidos, de Argentina a Brasil, de Chile a Francia, de Guatemala a México otra vez, y así, infinitamente, el fantasma de una coreografía colectiva, incómoda y tortuosa se levanta en diversas 
escalas. Y por supuesto, está la otra dimensión: el desplazamiento del ámbito rural a lo urbano en donde indígenas y campesinos son desplazados en contra de su voluntad, y aquí sus cuerpos son jugados. Es la diferencia entre la vida o la muerte.

Honrar la diferencia, acogerla, es lo opuesto a este escenario del horror. Escuchar las vergüenzas de una realidad que viven los migrantes africanos que circulan por los purgatorios e infiernos de las violencias de grupos criminales, y dolorosamente, de las mismas autoridades que deberían de protegerlos, expresan la urgencia de iluminar la sombra y de fomentar cambios positivos hacia un tránsito digno y libre que garantice el derecho a migrar y el derecho a no migrar, a existir ahí donde uno siente pertenencia.

La indiferencia: la peor de las actitudes. Es cierto, las razones para indignarse pueden parecer hoy menos nítidas o el mundo, demasiado complejo. ¿Quién manda?, ¿quién decide? No siempre es fácil distinguir entre todas las corrientes que nos gobiernan. Ya no se trata de una pequeña élite cuyas artimañas comprendemos perfectamente. Es un mundo vasto, y nos damos cuenta de que es interdependiente. Vivimos en una interconectividad como no ha existido jamás. Pero en este mundo hay cosas insoportables. Para verlo, debemos observar bien, buscar. Yo le digo a los jóvenes: buscad un poco, encontraréis. La peor actitud es la indiferencia, decir «paso de todo, ya me las apaño». Si os comportáis así, perdéis uno de los componentes esenciales que forman al hombre. Uno de los componentes indispensables: la facultad de indignación y el compromiso que la sigue. (Hessel, 2010, p.15)

De la misma manera, apelemos todavía a

una verdadera insurrección pacífica contra los medios de comunicación de masas que no proponen otro horizonte para nuestra juventud que el del consumo de masas, El desprecio hacia los más débiles y hacia la cultura, la necia generalizada y la competición a ultranza de todos contra todos". A aquellos que harán el siglo XXI, les decimos, con todo nuestro afecto: «Crear es resistir. Resistir es crear.» (Hessel, 1998, p. 24)

Y como si fuera poco, cabría preguntarse sobre el miedo a los fantasmas, los espectros, los encantos de sirena, ¿qué hombre es el que tiembla por sus propias ideas? Para garantizar la paz perpetua, de esos cuerpos que caminan invisibles, agónicos, de aquí para allá, deberíamos contemplar otra vez su naturaleza carnal, repertoriar cada uno de sus sentidos, de sus gestos, de sus experiencias; contemplar de nuevo un cuerpo legítimo, un cuerpo humano en carne y hueso, un cuerpo violentado por las políticas de los territorios; un cuerpo que es y seguirá siendo máquina de guerra, a la vez testimonio y archivo vivo, cuyo grito nos espanta al reconocer que estar o no estar, pertenecer o no, huésped o anfitrión, son condiciones fáciles de adquirir al simple trazo de una nueva y delgada línea imaginaria.

Pasan y los vemos pasar indiferentes.

Salamalekum, nangadef / Hola ¿qué tal? Mangi fi rek / Estoy bien

Ngir yalla /Por favor

Ñigui si díamma /Están bien

Mayma ndoj ma naan /Dame agua para

beber

Jaare yef/alguien me puede ayudar?

Mangi dém /Me voy

Nuun / Nosotros

Mangi diëm cha pekku géedj /Me voy a la

playa/al mar

Ndimmbal / Ayuda

Mangi fi rek / Estoy bien

Mangi dém /Me voy

Mangi dém /Me voy

\section{Referencias}

Arendt, H. (2002). Nosotros los refugiados. Barcelona, España: Gedisa.

Didi-Huberman, G., y Giannari, N. (2018). Pasar, cueste lo que cueste. España: Shangrila Textos Aparte.

Hessel, S. (2010). ilndignez-vous ! Montpelier, Francia: Indigène éditions. Iglesia, A. M. (16 de julio del 2019). Sandro Veronesi: "Lo que está pasando en el Mediterráneo con los inmigrantes es un genocidio". Disponible en «https://theobjective.com/further/ sandro-veronesi-salvar-vidas-mediterraneo/»

Prosa, L. (2012). La trilogía de Lampedusa. Barcelona, España: Quercy. 
Veronesi, S. (2019) Salvar vidas en el Mediterráneo. Un panfleto intimo contra el racismo. Barcelona: Nuevos cuadernos anagrama.

Wolf, C. (1998). Medea. New York, Estados Unidos: Nan A. Talese.

\section{Webgrafía}

Asamblea Nacional de las Naciones Unidas. (2018).

Conferencia Intergubernamental encargada de Aprobar

el Pacto Mundial para la Migración Segura, Ordenada y

Regular. (Marruecos, 10 y 11 de diciembre de 2018). Tema

10 del programa provisional. Disponible en «https://undocs.

org/es/A/CONF.231/3» 